\title{
The New Normal: Black Psychic Subjectivity in Antwone Fisher
}

\author{
Badia Sahar Ahad \\ Loyola University Chicago, bahad@luc.edu
}

Follow this and additional works at: https://ecommons.luc.edu/english_facpubs

Part of the English Language and Literature Commons

\section{Recommended Citation}

Ahad, BS. "The New Normal: Black Psychic Subjectivity in Antwone Fisher." CR: The New Centennial Review 13(3), 2013.

This Article is brought to you for free and open access by the Faculty Publications and Other Works by Department at Loyola eCommons. It has been accepted for inclusion in English: Faculty Publications and Other Works by an authorized administrator of Loyola eCommons. For more information, please contact ecommons@luc.edu. c) (i) $(9$

This work is licensed under a Creative Commons Attribution-Noncommercial-No Derivative Works 3.0 License. (c) Michigan State University, 2013. 


\title{
The New Normal
}

\section{Black Psychic Subjectivity in Antwone Fisher}

\author{
Badia Sahar Ahad \\ Loyola University Chicago
}

In the "Postscript" of Freud Upside Down (2010), I used the 1949 film Home of the Brave as an example of what had historically been the problematic intersections between race and psychoanalysis. Specifically, I interpreted the film's final message as one that suggested that the racist attacks endured by Pvt. Peter Moss (James Edwards) throughout the course of his life had led him to become overly sensitive to encounters with all whites, whether they are racist or not, and thus that the racism he suffers is essentially his problem. The film's resolution to blame the victim is not only indicative of its problematic glossing of the vicious and ubiquitous racial violence that black soldiers encountered during World War II, but also of the way in which it submits to a rhetoric of universalism that the model of psychoanalysis (and Hollywood) readily provides. In that same "Postscript," I went on to note that the HBO series In Treatment, which ran for three seasons between 2008 and 2010, featured an interracial therapeutic relationship between Alex, a black 
Navy pilot, and Paul, his white therapist. Notable about this relationship is the way in which Alex and Paul are constructed as peers; the combination of Paul's therapeutic authority and Alex's keen intellect, professionalism, and arrogance produces an equalizing effect in which both men are able to transcend the specter of race and delve into more universal issues, like the loss of a parent and divorce. While the analyst/analysand dynamic in In Treatment is firmly located at the opposite end of the spectrum from a film like Home of the Brave, it also participates in the negation/glossing of race as a potentially formative aspect of Alex's subjectivity. Granted, Alex's representation as simply "human" is the stuff of which postracialists dream, but there is also something eerily familiar about the way Alex is made a universal subject vis-à-vis the show's elision of race. Ultimately, the problem I'm setting up here is that in following these paradigms, there is no way that psychoanalysis can account for the presence of a raced subject without being either "racist" or "colorblind." It is the insistent universalizing of the subject that has made scholars of African American literature and culture notoriously wary of psychoanalysis as a meaningful lens through which to interpret black subjectivity.

What is particularly notable about the 2002 film Antwone Fisher, then, particularly within historical cinematic interactions between therapists and black patients, is the way that the film acknowledges, rather than obscures or obliterates, race and racism as constitutive aspects of identity even within its rather traditional approach to psychoanalytic treatment. Antwone Fisher, based upon the real life story of Antwone Fisher, portrays Fisher's ascent from a childhood marked by abuse, neglect, and abandonment to manhood. Fisher, born in a correctional facility and never having known his mother nor father, is placed in a foster home where he becomes the recurrent casualty of emotional, physical, and sexual abuse. After a series of displacements that eventually lead to his homelessness, Antwone turns to the navy, ostensibly because there is nowhere else for him to go. After being involved in an altercation with a white naval officer, Antwone is "punished" by having to undergo three sessions of psychiatric treatment with a naval doctor, Dr. Jerome Davenport. This interaction leads him on a journey to "find his family," confront the root of his traumatic experiences, and begin the healing process. 
Significantly, during the course of Antwone's treatment, he and Dr. Davenport engage in an exchange of written texts-Dr. Davenport gives Antwone copies of John W. Blassingame's The Slave Community and The Philosophy and Opinions of Marcus Garvey and Antwone recites for Dr. Davenport his own poem "Who Will Cry for the Little Boy?" I want to argue that by interspersing Antwone's psychoanalytic treatment with textual narratives of racial oppression, racial resistance, and racial pride, the film presents a case for both the universal elements of Antwone Fisher's trauma (and the attendant promise of a "cure"), and the racial particularity that undergirds his turbulent past. In doing so, the film remarkably negotiates the tension between Antwone's figuration as both a racial subject and a "universal" subject of psychoanalysis. Through an analysis of the film's representation of the psychoanalytic process, I'd like to suggest that Antwone Fisher reveals an evolution in the course of cinematic representations of black analysands, in which the line between racial specificity and psychoanalytic universalism is deftly mediated to allow the black subject of psychoanalysis a space of representation. By presenting a racially-inscribed psychoanalytic process, the film not only acknowledges race as a formative aspect of identity, but also offers a way to reconcile two seemingly different modes of inquiry, identity politics, and psychoanalytic interpretation, without enacting a process of cultural, ethnic, or racial erasure. I begin with a discussion of the critical tensions surrounding Antwone Fisher to read the film's arguable shortcomings as necessary to produce a particular brand of black masculine subjectivity that psychoanalytic discourse has traditionally rejected. I then turn to an analysis of the intraracial therapeutic dynamic, specifically the identificatory underpinnings of Antwone's relationship with Dr. Davenport, as well as the film's subtle, yet distinctive, inclusion of Blassingame's and Garvey's works, which concretizes the film's insistence, and my argument that race functions as a constitutive element of a subject's psychic life, significant given psychoanalysis's relentless claims to a raceless universality. Such has been the argument of scholars such as Hortense Spillers and Claudia Tate, who initiated the conversation concerning race and psychoanalysis asserting that "psychoanalysis can tell us much about the complicated social workings of race in the United States and the representations of those workings in the literature of African Americans" 
(Tate 1998, 5; Spillers 1996). I would extend this to include other narrative works that can help elucidate the psychical underpinnings of race within U.S. social networks and, particularly, the ways in which race is foundational to the psychic construction of individual subjectivities.

B REAKing Boundaries: A Matter of Method

Despite what I find to be Antwone Fisher's critical intervention in the negotiation of race and psychoanalysis made possible primarily through the explicit inclusion of black nationalist narratives, there are critics who have been especially disdainful of film's reliance upon so-called "race texts." In his rather scathing review of Antwone Fisher, "Leaving the Others Behind," David Walsh argues that "Antwone Fisher, whatever the conscious motives of the screenwriter and director, bears the mark of a narrow and retrograde socio-cultural moment. Instead of anger over the conditions ultimately responsible for Fisher's misfortunes, it offers racial pride, self-help advice and facile psychology" (Walsh 2003). Walsh goes on to critique the film's explicitly racial overtones:

At one point Davenport hands Antwone a copy of John Blassingame's The Slave Community (1972) and argues that his foster family's sadistic behavior is the result of having internalized abuse suffered by their slave ancestors. Without question the centuries-long experience of slavery must leave enduring psychological scars but patterns of abuse are hardly restricted to one or another ethnic group. They find their most general roots in a society based on the exploitation, continuously enforced by violence of the threat of violence, of one class by another, which inevitably distorts every human relationship. Which book would Davenport offer to a white sailor with a history of abuse? (n.p.)

Driven largely by Marxist imperatives, rather than identity politics, Walsh's critique functions as a mere microcosm of a larger, broader resistance to intersections of race and psychoanalysis echoing an even more recent imperative within academia to efface identity politics in favor of class. While scholars of African American studies have resisted the hegemonic paradigm of a Freudian universal subject, Walsh critiques the film's racial particularities, noting that the "film is not 
overtly racialist in its outlook, or insofar as it is, this is merely the default setting of many contemporary black (and female and gay) artists, who accept uncritically the assumptions of so-called identity politics." In other words, the film's recognition that Antwone's "blackness" may play even a partial role in his "misfortunes" signals the film's failure at its very premise, despite the fact that roughly " 37 percent of the children in foster care are African American despite the fact that African American children make up only 15 percent of the children living in the United States" (Wulczyn and Lery 2007, 1).

While choosing to simply ignore Walsh's hypothetical concerning which book the fictional Dr. Davenport would give to an even more hypothetical white sailor, I would like to offer a more productive line of inquiry that asks this question: how might the inclusion of black nationalism work within the traditional context of a Freudian talking cure to make possible a more salient psychoanalytic space for the black subject? Ironically, the film has been criticized by many practicing therapists as painting an overly celebratory picture of the patient/analyst interaction and suggesting that the "rapid cathartic cure is largely an invention of Hollywood that has come about as a necessity in order to add dramatic elements to a process that would otherwise appear dull and uninteresting" (Macfarlane 2004, 177). Further, it has been noted that the "portrayal of 'wonderful' psychiatrists as always being available ('You can phone me, day or night'), willing to bend the rules, and open to (if not encouraging) social contact out of hours is also potentially harmful, setting up an expectation of these boundary violations as a necessary part of the therapy" (177). What strikes me as particularly notable about this critique is the emphasis on the lack of necessary distancing that would conventionally be part and parcel of the patient/doctor interaction. However, absent from this critique is the recognition that through its unconventional boundary breaking, the film makes clear the necessity for a revised analytic model. Here I invoke Spillers's concept of psychoanalytics, which calls for a more loosely defined "psychoanalytic culture criticism" not bound by the strictures of psychoanalytic theory nor the parameters of traditional therapeutic exchanges (Spillers 1996). In many respects, the film acknowledges the failure of therapeutic institutions, particularly their failure to protect and meet the needs of black boys who constitute a disproportionate number of the children in social service and foster care systems. ${ }^{1}$ 
Specifically, the film argues for an analytic revisionism that goes against the grain of the traditional therapeutic experience; first through inclusion of racially-inflected narratives, which is indicative of the film's argument concerning racial factors as ingrained in the subject's psychological constitution; and second in its representation of an intraracial analyst/analysand relationship between Antwone and Dr. Davenport, which encourages a brand of identification rarely seen in cinematic therapeutic interactions. As such, my reading of Antwone Fisher flies in the face of the Western psychoanalytic model that has historically, and even presently, been inattentive (at best) to matters of race and, consequently, has been the object of derision by scholars in the field of African American studies. But, as the opening of this essay indicates, Antwone Fisher is located along a cinematic continuum of films in which the black male military subject serves as the analytic object-to various degrees of "success." To be clear, I do not claim that the film is free of frequent and disturbing missteps. While I interpret the film as one that effectively toes the line between the racial and the universal, Frank Wilderson reads Antwone Fisher as "safe politically and unsullied philosophically because it is able to deploy the Black (male) not as a creature desiring access to White beds, nor as a social opportunist desiring access to White institutions ... but as an ontological entity in the 'true,' 'universal,' sense of the word, someone who seeks only to realize his own being” (2010, 110). In Wilderson's view, Antwone Fisher's representation as "universal" subject is largely made possible by assigning and displacing the contempt and disdain, typically reserved for the black masculine subject, onto the black woman. About this, Wilderson's analysis is astute. The film so demonizes black femaleness in general, and black motherhood in particular, that one (almost) forgets Fisher's would-be abject status-for his ability to even attempt to overcome the abuse and alienation which has come to define him creates a heroic figuration. However, Wilderson's version of Antwone Fisher as a subject whose universality is assumed and which operates uncomplicatingly as a "force of law" is more difficult to digest, if only because the film marks blackness, generally speaking, as a psychic stumbling block that all blacks must work to overcome. 
To the extent that the film makes possible Antwone Fisher's psychic transformation, it constitutes a watershed moment in representations of the black analysand: Fisher's blackness does not forever relegate him to the land of the abject. However, the film cannot do this without significantly revising the psychoanalytic model, which has heretofore been interpreted as the film's most egregious "flaw": that Antwone Fisher is able to experience anything in the way of a psychological evolution. Indeed, the figure of Antwone Fisher embarks upon a rather paradigmatic version of what Spillers refers to as a strategy of "interior intersubjectivity," which "is not an arrival but a departure, not a goal but a process, and it conduces toward neither an answer nor a 'cure,' because it is not en-gendered in formulae and prescriptions. More precisely, its operations are torque-like to the extent that they throw certainty and dogma (the static, passive, monumental aim) into doubt” (1996, 84). Significantly, this "process" is one that is necessary for the realization of one's sense of subjecthood, both as an individual and within the context of a larger community.

\section{INTRARACIAL IDENTIFICATIONS}

The psychical life of the raced subject has been a matter of question and debate since as early as the Enlightenment-the historical moment when theories of black inferiority were solidified and made available for global consumption. Alternatively, there exists a host of edited volumes and scholarly texts that argue for the presence and salience of a "black psychology," most notably the collection Black Psychology, edited by Reginald L. Jones. First published in 1972 and now in its fourth edition, Black Psychology was compiled to fill the lacunae in psychological literatures dealing with black subjectivity. In these texts, a theory or approach of black psychology emerges as a necessary response to more traditional renderings of the black subject, which consistently misinterpret not only the black subject but also the machinations of black social and familial life. For example, reading black subjectivity through the lens of traditional psychoanalytic paradigms has, according to James Jones, "evolved a conception of race and its role in social life that is unfocused, underdeveloped, simpleminded, atheoretical, and consequently 
of little value in understanding contemporary trends in the world arena" (1991, 442). Despite the range of psychological approaches proffered in the volume, each proceeds from the common assumption that it is virtually impossible to properly analyze and/or theorize the black subject without taking into account slavery and institutional racism. With that, the filmic representation of Antwone Fisher's therapeutic experience bolsters the argument that the recognition of racial forces in the psychic life of black analysands is integral to the efficacious treatment of the "whole" person. Dr. Davenport's mixed methodthe application of a traditional psychological approach, specifically talk therapy combined with the invocation of black historical and black nationalist texts-produces, for the first time in the cinematic realm, a space for the primacy of black subjective experience. I would also contend that Dr. Davenport's own blackness serves as an effective point of identification for Antwone, who desires a tangible model of black masculinity, which Dr. Davenport epitomizes through his marital status (to a beautiful woman no less), his position as a high ranking military officer, and his sharp intellect.

Because of his initial resistance to psychological therapy, Antwone refuses to speak in his first sessions with Dr. Davenport. The film displays Antwone's stubborn refusal to be analyzed via repeated shots of his back turned toward Dr. Davenport, or Antwone standing defiantly in the corner of the doctor's office. Dr. Davenport, the epitome of the cool-headed analyst, does little to persuade Antwone to engage in the sessions; instead, he simply tells him that the first session will not begin until Antwone speaks. Realizing that his refusal to engage will only result in his having to attend more than the mandatory three sessions, Antwone finally opens up to Dr. Davenport about his earliest childhood memories. Within moments of Antwone Fisher's first full session with Dr. Davenport, he reveals the site of his trauma-the foster home of Mr. and Mrs. Tate. I identify Antwone's experience with Mrs. Tate as the locus of Antwone's traumatic experience because it is the images of abuse in her home that dominate Antwone's frequent nightmares. While Antwone's trauma manifests itself in his dream state as well as in his acts of physical rage, the most "effective cure [for such trauma] is sought by means of an abreaction and a psychical working out of the traumatic experiences" (LaPlanche and Pontalis 1973, 466). An "abreaction" is an "emotional discharge whereby the 
subject liberates himself from the affect attached to the memory of a traumatic event in such a way that this affect is not able to become (or to remain) pathogenic" (1). The concept of "abreaction" is a compelling one because it requires the subject not to detach from the memory of the traumatic event, but instead from the sensation or "affect" the memory produces. An abreaction, then, is an emotional reframing of one's response to a traumatic past.

Antwone's psychical journey thus necessitates ridding himself of the feelings of anger, shame, and fear associated with his childhood in the Tate home. Antwone was separated from his family in violent and destructive ways, only to be placed into an abusive surrogate/foster family; this illuminates the significance of the film's first scene. At the opening of the film, the camera pans over a field of wheat, and in the midst of this vast field stands a young man about the age of 11, presumably a young Antwone. We find young Antwone gazing wistfully upon a massive barn. In the next moment, Antwone is at the door of the barn being greeted by a hulking black man whose warm smile and extended hand betray his otherwise foreboding appearance. Antwone is led into the barn, where he is met by dozens of people crowded around a dinner table filled with a bounty of fruits and flowers. The "family" represented in this scene features figures adorned in the "coarse linens" worn by slaves: 1970s style polyester suits, Victorian era gowns and frock coats, and early-twenty-first-century fashions. All of the guests at this event smile and wave lovingly to Antwone as he takes his seat at the head of the table, where he is served a huge stack of fluffy pancakes drowning in butter. The family, as it is represented in the dream, emerges as a symbol of Antwone's desire/hope for a sense of belonging and the unconditional love that family is supposed to provide. We later learn that the pancakes, which play a prominent role in Antwone's familial fantasy, were indicative of the rare "good" days he experienced in Mrs. Tate's home; for Antwone, the smell of "grits and eggs" in the morning foretold a day in which Mrs. Tate was in a foul mood, but the scent of pancakes indicated an unusual instance of peace in the Tate household. The kinfolk of whom Antwone dreams are distinctive because they represent not only a longing for an immediate family, but also an ancestral one. Inasmuch as the film is staged such that Antwone's realization of an integrated self emerges as a heroic endeavor, it also emphasizes the necessity for Antwone to 
be identified within the context of a larger community, hence the emphasis on the ancestral history of a family in addition to an immediate family. However, Antwone Fisher points to the complexities of Antwone's seamless integration within a community, particularly within an African American community that is "more precisely ambivalent than any American case we can concoct" (Spillers 1996, 88). Any semblance of "home" for Antwone has been vexed, in both the literal and cultural sense of the term. This includes the military, which unabashedly promotes itself as a space that embodies ethicism, morality, fairness, and integrity. However, given Antwone's blackness, his experience is far different than that of "the traditional subject of psychoanalytic process [who] was de-ceptively 'at home' in the culture; he seemed to believe that he 'belonged,' whereas the minority subject does not start there" (Spillers 1996, 109).

Thus the film becomes a witnessing of Antwone's working out and working through his traumatic experiences and his abreaction is only made possible by finding his real family. In the course of his therapy sessions, Antwone's relationship with Dr. Davenport and his wife, Berta, develops significantlyso much so that Dr. Davenport begins to refer to Antwone casually as "son." Of course, from a psychoanalytic perspective, Dr. Davenport's use of the term signals, perhaps, an inappropriate substitution of the therapist in the role of father, which could potentially lead to an unhealthy dependence. However, it is also important to recognize the term "son" as it operates in the African American vernacular, as in "what's up, son," as a gesture of kind familiarity and friendship. While Dr. Davenport's potentially unproductive reference to Antwone as "son" may be indicative of the film's boundary-breaking between therapist and patient, such transgressions can be read as necessary. The extension of Dr. Davenport's role beyond that of mere "therapist" to include that of mentor, teacher, role model, and witness becomes crucially important for Antwone’s emergence as an integrated subject. According to Mieke Bal,

it is suggested that the incapacitation of the subject-whose trauma or wound precludes memory as a healing integration — can be overcome only in an interaction with others. This other is often a therapist, but can be whoever functions as the "second person" before or to whom the traumatized subject can bear witness, 
and thus integrate narratively what was until then an assailing specter. In other words, a second person is needed for the first person to come into his-or herself in the present, able to bear the past. (Bal, Crewe, and Spitzer 1999, xi)

Dr. Davenport not only functions as a witness to Antwone's "testimony," which thereby enables him to articulate the past and move forward in the present, but he also serves as a model of black masculinity, which the film portrays as a paradigmatic void in Antwone's life that can (and should) be filled vis-à-vis his relationship with Dr. Davenport.

Despite what, on the surface, may appear to be an idyllic familial model in which Dr. Davenport and Berta provide an adequate substitute for Antwone's absent parents and Antwone can enjoy the role of son for the childless Davenports, the film does not allow for such facile resolutions. At the moment when it seems as though Antwone has, indeed, "found his family" with the Davenports, Dr. Davenport ends their sessions and sends Antwone on what will become an emotionally-charged physical journey to locate his biological family. With his new girlfriend in tow, Antwone retraces the path of his childhood, which invokes a final confrontation with Mrs. Tate and learns his father's name. He subsequently finds his real family and undergoes a hearttugging meeting with his biological mother, in which he forgives her. While the film refuses to enable Dr. Davenport to act as a surrogate father for Antwone, he does serve as Father (as in The Name Of ... ). Because Antwone lacks a relationship with his biological father, Dr. Davenport becomes for Antwone not only a model of black masculinity but also a model of institutional authority (vis-à-vis his high naval ranking) and of heteronormativity (he teaches Antwone how to "court" a woman). In his role as psychoanalyst, Dr. Davenport ushers Antwone into the Symbolic Order and manifests his identification with it, thereby mitigating Antwone's abjectness by both creating a space (within psychoanalysis) for his own narrative and providing him with written texts that only enhance that narrative's meaning.

While the film's insistence upon Antwone's proper insertion within the Symbolic Order is noteworthy in terms of its refiguring of the black analysand, the framing of Dr. Davenport offers a revision of historical representations of the black analyst. As I've mentioned elsewhere, through the example of Home 
of the Brave and In Treatment, the interracial therapeutic dynamic in film and television is most often binarily represented as either overtly racist or explicitly nonracial. Ironically, the 1962 film Pressure Point, produced by Stanley Kramer-who also served as producer for Home of the Brave-may be one notable exception. In Pressure Point, the Doctor (played by Sidney Poitier) is charged with providing treatment for an inmate who identifies as a Nazi sympathizer. Initially refusing therapy from a "Negro" doctor, the Patient realizes that undergoing treatment with the "Negro" Doctor is his only recourse to quell what may best be described as panic attacks. His desperation drives him to seek treatment from the Doctor and, in the course of the sessions, he comes to realize, with the Doctor's assistance, that his racism against blacks and Jews may be more deeply rooted in his latent anger toward his abusive father. In a rather paradigmatic turn, the film elides the cultural life of the U.S. in the 1950s and 1960s, also known as the Civil Rights era, that would effectively work to produce and reinforce the Patient's racist attitudes toward blacks; in particular it suggests that the Patient's identification with Nazis emerges from a dysfunctional childhood in which he was forced to endure the abuse of his father and console his weak mother. While Pressure Point may be problematic in its refusal to acknowledge the racial dynamics emerging out of the Civil Rights era, the film is distinctive in the way in which it foregrounds the racial difference between patient and doctor as a significant aspect of the therapeutic relationship. In addition, that the Doctor, an African American psychiatrist, stands in the position of power both as medical authority and “free" subject (compared to the Patient's prison status), uniquely constructs the analyst/analysand dynamic by providing a leveling of sorts in which the Patient's white heteromasculinity is undermined by the [black] Doctor's positionality.

I take Pressure Point as one of the few cinematic representations of the interracial therapeutic dynamic in which race functions as a formative aspect of the relationship but is not overdetermined by it. Other than the sheer coincidence that Denzel Washington largely has been described as Sidney Poitier's heir apparent, Pressure Point bears an important relation to Antwone Fisher in the way it constructs the therapeutic relationship as one in which race matters, either at the level of interpersonal interaction or historical 
memory. However, in Pressure Point, race only matters to the extent that it can enable an affective bond between interracial subjects, which is also the case in the relationship between Mingo and Moss in Home of the Brave. Similar to Home of the Brave, then, Pressure Point "features a treatment relationship which foregrounds the reinforcement of patriarchal relations between men, doctor and patient, as a solution to racial prejudice" (Slane 2004, 61). Clearly this is one point in which the intraracial relationship represented in Antwone Fisher departs from its cinematic predecessors. Andrea Slane's thorough analysis of Pressure Point reveals yet another crucial distinction from Antwone Fisher: Pressure Point facilitates the interracial connection between the Doctor and the Patient by aligning blackness with "maternal weakness" (60). As Slane puts it, "as African American women are undertheorized in both psychoanalysis generally and in the film's version thereof, what this logical convolution reflects is the film's efforts to offer Poitier's persona as a substitution for the racist image of the brutal black man-but it does so by aligning him with the patient's mother" (6o). Though I do not read the Doctor's question- “Don't you feel sorry for people who are weak?"-as necessarily an admission of his weakness nor as stratagem to garner the white patient's pity, given the historical impetus to feminize African American men, it becomes clearer why a film like Antwone Fisher is deeply invested in asserting the heteromasculine subjectivity of its black psychiatrist and its black analysand. ${ }^{2}$

\section{Narrativizing The Self}

As mentioned earlier in this essay, Antwone Fisher draws upon three texts as referential markers in Fisher's psychoanalytic journey-Blassingame's 1979 The Slave Community, The Philosophy and Opinions of Marcus Garvey and a poem, "Who Will Cry for the Little Boy?" written by the actual Antwone Fisher, upon whose life the movie is based. The film's inclusion of these texts suggests that for Fisher to overcome his traumatic childhood experiences there is a particularized racial knowledge that must be acquired to achieve selfknowledge. For Fisher to be able to come to terms with what has happened to him in the past, he is forced to acknowledge that he (and his tormentors) are 
part of a historical cycle of white supremacist subjugation that he must fully unearth and understand before he begins to resolve it. Because white dominant authority, particularly in terms of character interaction, is barely visible in the film, the sense of a looming racialized oppression only emerges in the psychical register, which manifests itself in Fisher's seemingly inexplicably enraged responses to what appear to be fairly minor confrontations. Interestingly, the fight that lands Antwone in Dr. Davenport's office begins when a white soldier jokingly asks Antwone, "What's that on your face?” Of course, the punchline for this joke is generally "your face," intimating that the subject of the joke is physically unattractive. However, we never hear the punchline, because once the white soldier starts the joke, Antwone immediately nails him to the ground and a fight ensues. It is not until Antwone is facing a tribunal for assaulting a senior officer that his defense rests upon the fact that the offending soldier made a racist remark. What complicates what would be Antwone's legitimate reaction to a racist joke is the aloofness he demonstrates when recalling the details of the tribunal to his fellow soldiers. At this moment, it is unclear whether or not Antwone honestly believed he was the victim of racism, or if he merely used racism as an excuse to justify his assault. In Wilderson's interpretation of the film, white authority does not function as a psychical force, but emerges more tangibly in the characters of Mrs. Tate, who fosters Antwone, and Cousin Nadine, who routinely sexually abuses him. For Wilderson, these characters function as surrogates for white subjugation. He notes that "we find not one White hand at the end of all the literal and figurative whips that cut deep into Antwone Fisher's back and psyche. Instead, we have the figure of three Black women" (2010, 101-2). Further, he argues that "it is black femininity that delivers [Antwone] from niggerhood, so that his ethical dilemmas can be negotiated within a frame of reference" (101). However troubling, Dr. Davenport's reference to Blassingame's The Slave Community imbricates Mrs. Tate and her daughter within the same historical web in which Antwone is trapped. And, in an interview, the actual Antwone Fisher admits that the filmic representation of his foster home is a generous one. ${ }^{3}$

To interpret the behavior of Antwone's abusers as equally constructed by individual malice and within an historical continuum of institutional oppression 
may account for a slightly more sympathetic read of the Tate family, who could otherwise be largely construed as uncomplicatingly evil and pernicious. Published in 1972, John Blassingame's The Slave Community has been touted as the first text to examine "slave personality types" and the psychological underpinnings of each. In fact, Blassingame dedicates the entire seventh chapter of The Slave Community to "Slave Personality Types," beginning with a discussion of Harry Stack Sullivan's "interpersonal theory." Sullivan was a prominent psychoanalyst during the post-World War II era and a personal friend and collaborator of sociologists Charles Johnson and E. Franklin Frazier. Sullivan is perhaps best known for his break with Freudian interpretations, which he believed relied too heavily on familial dynamics and did not fully account for the ways that social and environmental factors like poverty, racism, and discrimination affected one's psychological state (Hale 1995, 17576). Using Sullivan's interpersonal theory, which claims that "behavioral patterns are determined by the characteristics of the situation, how the person perceives them, and his behavioral dispositions at the time," Blassingame constructs a slave-master relation in which the slave is "so oppressed that [he] accepted [his] master's claims about the rightness, the power, and the sanctity of whiteness and the degradation, the powerlessness, and the shame of blackness" (Blassingame 1979, 185, 199). While profiling many slave types that both implicitly and explicitly rejected white supremacist logic, Blassingame notably points to those slaves for whom identification with a white master was a sign and symbol of the internalization of white authority. To invoke yet another black analytic figure, psychiatrist Frantz Fanon takes up this idea of black complicity and identification with white hegemony in The Wretched of the Earth, in which he writes that "the native is an oppressed person whose permanent dream is to become the persecutor" (Fanon 1963, 53). While the colonial situation that Fanon describes is specific to the colonial situation in Algeria, the spirit of his remark deeply resonates with the experience of blacks in the United States.

While it may not be unusual for a therapist to offer a patient a textual resource to complement the therapeutic process, Davenport's choice underscores the significance of racial knowledge in Antwone's psychical evolution and thus undercuts the idea that it can be understood in universal terms. 
Specifically, in one of his sessions with Dr. Davenport, Antwone goes into great detail, highlighting the ways that Mrs. Tate's torment was punctuated by her refusal to call him by his name, only referring to him and his darkcomplexioned foster brother, Dwight, as “nigger.” Mrs. Foster's consistent use of "nigger"-a derogatory term appropriated from the lexicon of white supremacy-and her preferential treatment of Keith, Antwone's fair-skinned biracial foster brother, categorically places her among those self-hating and self-deprecating slave personalities and reveals her own internalized racism. After listening to Antwone's response to Mrs. Tate's consistent privileging of the lighter-complexioned Keith, and specifically Antwone's admission that as a child he "wished [he] was Keith,” Dr. Davenport insists that Antwone understand his experiences within the context of a historical slave past, which produced a legacy of psychological oppression and self-hatred from which blacks have been unable to escape. Essentially, then, Dr. Davenport looks past the relative immediacy of his experience in Mrs. Tate's home to locate the origin of Antwone's pain as arising out of the context of slavery. While the viewing audience is not at all meant to experience any form of sympathetic identification with Mrs. Tate, Dr. Davenport recognizes that she, too, is part of a broader historical landscape in which blackness functions as the inferior Other. While the acknowledgment of Mrs. Tate's internalization of black inferiority does little to absolve her cruelty toward Antwone, it does highlight/ underscore the ways that white supremacist logic emerges as a psychological presence even in the absence of a white physical body.

Inasmuch as the dynamics of the film revolve around the circumstances of Antwone's abuse, the film is also invested in its portrayal of Antwone as the anti-victim. When he gives Antwone a copy of The Slave Community, Dr. Davenport explains to him that it would be "helpful to understand the mentality of people like the Tates." Antwone accuses Dr. Davenport of "taking up for them," at which point Dr. Davenport responds that "this is not about them. This is about you." In many respects, Dr. Davenport wants Antwone to develop a sense of historicity with respect to his own "narrative." In the process of relating his story to Dr. Davenport, Antwone draws upon the fragmented moments of shame and abuse he suffered as a young boy. However, what Dr. Davenport offers him in Blassingame's and Garvey's works is a narrative lens 
through which to better understand and contextualize his story. In this way, Dr. Davenport not only recognizes Antwone as both a psychoanalytic subject and as a subject of history: he acknowledges Antwone as a subject of discourse.

Positioning one as such typically serves as a reminder that the individual is always already imbricated within a linguistic, social, national, and ideological framework, thus establishing the very limits of that fantasy called agency. However, the film so fully and so successfully constitutes the prepsychoanalytic Antwone as one without referent; therefore, his integration within hegemonic institutions (military, psychoanalytic, familial) reads as a desirable achievement. While traditionally the heroic subject, particularly within African American narratives, acquires agency through the disavowal of institutional power and authority (Ellison's invisible narrator comes to mind here), Antwone Fisher not only desires but epitomizes normative belonginguniversality. Hortense Spillers warns us of the ease with which one may locate himself within Freud:

It seems that Freud wrote as if his man/woman were Everybody's, were constitutive of the social order, and that coeval particularities carried little or no weight precisely be-cause its theories seduce us to want to concede, to "give in" to its seeming naturalness, to its apparent rightness to the way we live, we must be on guard all the more against assimilating other cultural regimes to its modes of analyses too quickly and without question, if at all. (Spillers 1996, $86-87)$

However, for the raced subject who has historically been located outside such paradigms of the interior, the lure of normative assimilability without racial erasure has never been so attractive. It is the seduction, the "giving in," that registers in Antwone Fisher as the very act that will bring the subject of analysis into full relief. Thus, the film's discursive emphasis on narrative subjectivity, in both the practice of psychoanalysis and the inclusion of race texts, makes clear its goal to execute Antwone's black masculinity as a site of racialized normativity, actively constituted in and through a national and historical discourse. By fashioning Antwone as a subject of discourse, in the spirit of the 
formula that narrative and psychoanalysis so readily provide, he transcends the abjectness of black maleness and its attendant denigration to simply being in and of this world.

Further, the dialogue is not meant to absolve the Tates of the wrongs they committed against Antwone and his foster brothers. However, it does serve to disincline the audience from interpreting Antwone solely through the lens of victim; conversely, it sets up the conditions for Antwone's heroic ascension. Reframing Antwone's potential victimhood in this way is reminiscent of Paula Vogel's rendering of the victim in her controversial play, How I Learned to Drive. Vogel notes that "we are now living in a culture of victimization, and great harm can be inflicted by well-intentioned therapists, social workers, and talk show hosts who encourage people to dwell in their identity as victim without denying or forgetting the original pain. I wanted to write about the great gifts that can also be inside of that abuse" (Vogel 1997, 104). The physical and emotional abuse Antwone suffers at the hands of Mrs. Tate constitutes the film's most disturbing scenes as we witness her viciously beat the young boy unconscious with a wet rag and taunt him with fire while he is tied to a pole in the family's basement. However, the scene in which Antwone is sexually abused by Cousin Nadine is represented quite differently.

While babysitting young Antwone, Nadine instructs him to go "downstairs," which, at this point in the film, we've come to associate as the primary site of Antwone's physical and sexual abuse-the basement reads as the virtual torture chamber in which he and his foster brothers are routinely tormented. The audience never sees Nadine abuse Antwone; instead, the camera merely lingers outside the window of the basement and we hear Nadine instructing Antwone to touch her in ways that are entirely inappropriate between an adult woman and a child. Because this scene is not fully revealed, one must rely on the imagination to fill in the blanks-an act that proves even more distressing than the film's representations of explicit violence. Although the gendered implications of Antwone's maltreatment are problematic, as Wilderson rightly argues, it is significant that the "White hand"/body is mostly absent from the film's relational dynamics (2010, 101). In fact, the presence of a subjugating white body essentially would undermine what appears to be one of the film's more implicit themes: 
black self-reliance, which emerges most prominently in the film's invocation of Marcus Garvey, and which I discuss later in this essay. Yet, it is this insistence upon not relegating Antwone to the status of victim that structures what might be regarded as a somewhat sympathetic representation of the Tates, along with the relative absence of patriarchal white authority (though one could argue that the film's primary location on a naval base looms as such). Nonetheless, the film's strategic representations of Antwone's abusers and the absence of a tangible white authority problematizes the would-be uncomplicated binaries of white and black, as well as victim and abuser, to heroically figure Antwone into the seemingly paradoxical role of the raced, universal subject.

However, Antwone's heroic figuration is not only predicated upon his adherence to a heternormative matrix, particularly one that is predicated upon a hegemonic whiteness. The Philosophy and Opinions of Marcus Garvey provides for him a model of black masculinity with which he is meant to identify and, in fact, confronts and challenges the very terms of white authority. The insertion of Garvey's narrative at this stage in the film is a curious one, in that it does not directly nor explicitly bear any relation to the traumatic experiences that Antwone recounts. However, Dr. Davenport's gift to Antwone occurs at the moment when Dr. Davenport concludes his therapy sessions with Antwone, reminding him that the only way to work through his traumatic past is to "find his family," which he must do without the doctor's guidance. This separation between doctor and patient later emerges as a foreshadowing and foregrounding of Antwone's newfound agential self. Garvey's most famous assertion, "Africa for the Africans," is emblematic of his larger program of black autonomy in social, cultural, and economic spheres. As Beryl Satter notes,

faith in the importance of racial solidarity underlay the three goals of Garvey's UNIA: to arouse a unified race consciousness in all peoples of African descent, whether living in the United States, the West Indies, or Africa; to strengthen this united black race by organizing black-owned and managed, large-scale business enterprises and shipping lines; and finally, to create a black-governed 
nation in Africa that would host the creation of a renewed black civilization and stand up for the rights of black people everywhere. (Satter 1996, 44)

Garvey's narrative can best be described as a compilation of affirmations designed to inspire Africans in the diaspora to maintain and develop a sense of racial pride, to increase their faith in God, and to glorify Africa as a legitimate homeland. At the center of Garvey's program of racial pride was an intense focus on the articulation and practice of black masculinity. In a section entitled “Dissertation on Man," he writes:

Man is the individual who is able to shape his own character, master his own will, direct his own life and shape his own ends.... As far as the Negro race is concerned, we can find but few real men to measure up to the higher purpose of the creation, and because of this lack of manhood in the race, we have stagnated for centuries and now find ourselves at the foot of the great human ladder.... I desire to impress upon the 400,000,00o members of my race that our failings in the past, present and of the future will be through our failures to know ourselves and to realize the true functions of man on this mundane sphere. (Garvey 1969, 21)

I highlight this passage in particular because it encapsulates Garvey's formulations of black self-reliance and masculinity and its centrality to Garvey's vision of the future of the race. Further, the invoking of Garvey serves as a reminder of Antwone's blackness and the various forms of subjugation he experiences; yet, as the quote indicates, it simultaneously reinforces his figuration as universal man.

While the mantra "Africa for the Africans" (for which this text is most well known), may not have a direct bearing on the issues faced by Antwone Fisher, Garvey's rendering of masculinity and his emphasis on the notions of autonomy, agency, and divineness that constitute "Man" do work to shore up Antwone's position as a masculine subject in the most heteronormative and hierarchical sense of the term. Though the film refuses to make Antwone's sexuality a matter of question (though he is teased by his fellow naval officers 
for his refusal to "hook up" with women in the bars they frequent), his victimization at the hands of his pedophilic foster cousin produces a psychic wound that the audience is meant to interpret as the rationale/cause for Antwone's "late" virginity. So part of Antwone's abreaction is his coming into manhood, which he achieves both through the physical act of sexual intercourse with Cheryl and via his assertion of a masculine self in his final confrontations with both Mrs. Tate and his biological mother. In fact, the film constructs heterosexuality as Antwone's heroic gift. Framed by his reading of Garvey's work, the film thus posits a direct correlation between black masculinity and black consciousness.

Though Antwone's masculine construction is articulated along conventional lines, there is a moment that reveals the extent to which he is still "in process." When Antwone visits Dr. Davenport's home for Thanksgiving dinner, he shares with Dr. Davenport a poem he has written, entitled "Who Will Cry for the Little Boy?":

Who will cry for the little boy?

Lost and all alone

Who will cry for the little boy?

Abandoned without his own?

Who will cry for the little boy?

He cried himself to sleep

Who will cry for the little boy?

He never had for keeps

Who will cry for the little boy?

He walked the burning sand

Who will cry for the little boy?

The boy inside the man

Who will cry for the little boy?

Who knows well hurt and pain

Who will cry for the little boy?

He died again and again

Who will cry for the little boy? 
A good boy he tried to be

Who will cry for the little boy?

Who cries inside of me

Despite the film's allegiance to traditional, heteronormative models of masculinity, the moment in which Antwone reads this poem for Dr. Davenport reveals his vulnerability and his desire for a witness to his grief and an audience for his transformation. The poem is quite literally a call for help, for a sympathetic listener who will both acknowledge and participate in the pain of his experiences. The line, "Who will cry for the little boy? / The boy inside the man” also reveals a disjuncture between an exterior façade of maleness and masculinity and its attendant trappings and an interior defenselessness that is not entirely reconciled to its hard exterior. In Bal's formulation of narrative memory, she refers to its social function in which "the past makes sense in the present, to others who can understand it, sympathize with it, or respond with astonishment, surprise, even horror; narrative memory offers some form of feedback that ratifies the memory" (1999, x). In this way, Dr. Davenport is ideally situated to bear witness to Antwone's reclamation of self through the experience of listening. The poem not only reveals Antwone's penchant for creativity and cements his figuration as a burgeoning Renaissance man; it is also part of the important process of Antwone coming to terms with and creating his own story. Through his reading and his production of texts-all narrative acts-Antwone Fisher negotiates the difficult line between the "universal" psychoanalytic subject and the subject of race. The analytic situation itself is so thoroughly organized around methods of narration and storytelling that it marks Antwone's eventual healing as enabled by his ability to make meaning through his integration of these various discourses.

Though not without its flaws, Antwone Fisher marks a central and significant moment in the continuum of filmic representations of raced subjects and the therapeutic experience. In the end, the film attempts a rather remarkable feat (for Hollywood, at least), which is to offer the black male figure access to universality through his very racial particularity. Blassingame's and Garvey's works, while radical in their own right, function in the film as historical, cultural, and contextual markers of subjectivity. Antwone's compulsion to fill 
in the gaps of his fragmented existence, revealed in the deformed dream sequence in the film's first frame, is driven by a relatively modest goal-to exist as both an individual subject and a part of a communal whole. In this respect, Antwone Fisher "succeeds" as both subject and as film. The representation of psychoanalysis as enabling a "cure" works not only through the boundary-breaking treatment of the analyst but through the film's conflation and reliance upon the various forms of narrative that psychoanalytic interaction makes possible. Antwone's self-production emerges through both the telling of his story and his reading of texts locating him firmly within the space of discourse. Granted, a subject's insertion into the social order hardly reads as noteworthy much less celebratory; however, there is something quite remarkable about the seamless way that blackness stands, unwaveringly and unapologetically, front and center in Antwone Fisher's psychoanalytic project.

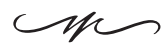

N O T E S

1. I use the term "therapeutic institutions" broadly to incorporate psychologists, psychiatrists, social workers, foster parents, and other relevant social service agencies.

2. The now infamous report, "The Negro Family: The Case for National Action," produced by sociologist Daniel Moynihan, has frequently been cited as exemplary of historical discourses that frame black families, in general, and black men, in particular, as weakened and pathological due to their deviance from conventional gender norms in which the male figure functions as the head of the household and the woman acts in a supporting domestic role. According to Moynihan and others, black families' history of households led by matriarchs is a holdover from the era of slavery in which black male patriarchal authority was subsumed by the power of white slaveholders (Moynihan 1965).

3. In an interview with Rebecca Murray, Fisher states that he "was kind to them in the movie and the book. I was kind to them. They are worse" (Murray n.d.).

\section{R E F E R E N C E S}

Ahad, Badia Sahar. 2010. Freud Upside Down: African American Literature and Psychoanalytic Culture. Urbana: University of Illinois Press.

Antwone Fisher. 2002. Dir. Denzel Washington. Perf. Derek Luke, Denzel Washington. Fox Searchlight Pictures. 
Bal, Mieke; Crewe Jonathan; and Spitzer Leo. 1999. Acts of Memory: Cultural Recall in the Present. Hanover, NH: University Press of New England.

Blassingame, John W. 1979. The Slave Community: Plantation Life in the Antebellum South. New York: Oxford University Press.

Fanon, Frantz. 1963. The Wretched of the Earth. New York: Grove Press.

Garvey, Marcus. 1969. The Philosophy and Opinions of Marcus Garvey. New York: Atheneum.

Hale, Nathan. 1995. The Rise and Crisis of Psychoanalysis in the United States: Freud and the Americans, 1917-1985. Oxford: Oxford University Press.

Home of the Brave. 1949. Dir. Mark Robson. Perf. Jeff Corey, James Edwards, Frank Lovejoy. Stanley Kramer Productions.

Jones, James. 1991. The Concept of Race in Social Psychology: From Color to Culture. In Black Psychology, ed. Jones Reginald, 441-67. Berkeley, CA: Cobb \& Henry.

LaPlanche, Jean; and Pontalis Jean-Bertrand. 1973. The Language of Psychoanalysis, trans. Donald Nicholson-Smith. New York: Norton.

Macfarlane, Stephen. 2004. Antwone Fisher: How Dangerous Is "Dr. Wonderful”? Australasian Psychiatry 12, no. 2: 176-78.

Moynihan, Daniel. 1965. The Negro Family: The Case for National Action. United States Department of Labor. http://www.dol.gov/oasam/programs/history/webid-meynihan.htm (accessed August 26, 2013).

Murray, Rebecca. n.d. The Real Antwone Fisher Interview. http://movies.about.com/library/ weekly/aaantwonefisherintc.htm (accessed September 29, 2012).

Pressure Point. 1962. Dir. Hubert Cornfield. Perf. Sidney Poitier, Bobby Darin. Stanley Kramer Productions.

Satter, Beryl. 1996. Marcus Garvey, Father Divine and the Gender Politics of Race Difference and Race Neutrality. American Quarterly 48, no. 1: 43-76.

Slane, Andrea. 2004. The Interracial Treatment Relationship in the Cold War Period: Pressure Point in Analysis. In Celluloid Couches, Cinematic Clients: Psychoanalysis and Psychotherapy in the Movies, ed. Brandell Jerrold R., 47-66. Albany: SUNY Press.

Spillers, Hortense. 1996. All the Things You Could Be By Now if Sigmund Freud's Wife Was Your Mother. Boundary 2 23, no. 3: 75-141.

Tate, Claudia. 1998. Psychoanalysis and Black Novels: Desire and the Protocols of Race. New York: Oxford University Press.

Vogel, Paula. 1997. How I Learned to Drive. New York: Dramatists' Play Service.

Walsh, David. 2003. Leaving the Others Behind. World Socialist Web Site, January 29. http:// www.wsws.org/en/articles/2003/o1/antw-j2g.html?view=print (accessed August 8, 2013).

Wilderson, Frank. 2010. Red, White and Black: Cinema and the Structure of U.S. Antagonisms. Durham, NC: Duke University Press.

Wulczyn, Fred; and Lery Bridgette. 2007. Racial Disparity in Foster Care Admissions. http:// www.chapinhall.org/research/report/racial-disparity-foster-care-admissions (accessed September 20, 2012). 